\title{
INVESTIGAÇÃO DA INFLUÊNCIA DE FATORES DE FORMAÇÃO NO DESENVOLVIMENTO DE RECOBRIMENTOS POLIMÉRICOS VIA LAYER-BY-LAYER SPIN COATER.
}

\author{
Bruno S. Leão*, João B. M. R. Neto, Marisa M. Beppu.
}

\section{Resumo}

Com o objetivo de investigar a influência de parâmetros de formação nas propriedades físico-químicas de recobrimentos poliméricos produzidos pela técnica de Layer-by-Layer spin coating, foram desenvolvidos filmes contendo 10 bicamadas utilizando os pares de polieletrólitos SPS/PDAC (poli(4-estirenosulfonato de sódio) e poli(cloreto de dialildimetilamonio)) e HA/CHI (ácido hialurônico e quitosana) em substratos de silício. Foram variadas, de maneira geral, as seguintes condições: velocidade de rotação do substrato, concentração das soluções poliméricas utilizadas, grau de acetilação e $\mathrm{pH}$ das soluções poliméricas. Os filmes foram caracterizados via Espectroscopia de UV-Vis e Microscopia de Força Atômica (AFM) com módulos de KPFM e dC/dZ. Paralelamente, filmes de 10 e 20 bicamadas foram produzidos pelo método imersivo nas mesmas condições de concentração para fins de comparação.

\section{Palavras-chave:}

Layer by layer, spin coating, filmes finos.

\section{Introdução}

A técnica de Layer-by-Layer (LbL) baseia-se na deposição alternada de dois ou mais materiais que se ligam fisicamente promovendo a formação de filmes multicamadas, cujas aplicações podem estar relacionadas a energia, catálise, produção de membranas, biomedicina, entre outras ${ }^{1}$. Contudo, a escolha do método para a adsorção dos materiais, dentre os diversos existentes, determina as características e as propriedades dos filmes. Sendo assim, o conhecimento do impacto gerado pelos fatores de formação de cada método é necessário para que se atinjam as propriedades desejadas nos recobrimentos poliméricos.

Dessa maneira, o presente trabalho consiste na produção de filmes em diferentes condições de formação pela técnica Layer-by-Layer, utilizando-se do método spin coating, com o intuito de entender a influência da velocidade de rotação do substrato, da concentração das soluções utilizadas, do $\mathrm{pH}$ do meio e da natureza do par de polieletrólitos escolhido. Além disso, também foi realizada uma comparação entre as propriedades moduladas via spin e aquelas alcançadas via dipping coating (método imersivo) com recobrimentos produzidos em condições similares de formação.

\section{Resultados e Discussão}

Foram produzidos filmes poliméricos de 10 bicamadas com o par de polieletrólitos SPS e PDAC através do método de spin coating, utilizando-se 2000 RPM e 4000 RPM como velocidades de rotação do substrato e 0,01 M e $0,05 \mathrm{M}$ como concentração das soluções poliméricas utilizadas. Paralelamente, foram produzidos filmes de 10 e 20 bicamadas por dipping variando, contudo, somente a concentração das soluções. As Tabelas 1 e 2 apresentam os resultados de espessura e rugosidade dos recobrimentos, respectivamente. Os resultados dos filmes de $\mathrm{HA} / \mathrm{CHI}$ estão sendo analisados e serão apresentados no relatório final e no pôster.

Tabela 1. Espessura média dos filmes [nm].

\begin{tabular}{|c|c|c|c|}
\cline { 2 - 4 } \multicolumn{1}{c|}{} & \multicolumn{2}{c|}{ Spin } & Dipping \\
\cline { 2 - 4 } \multicolumn{1}{c|}{} & $2000 \mathrm{RPM}$ & $4000 \mathrm{RPM}$ & 20 bic \\
\hline $0,01 \mathrm{M}$ & 30 & 26 & 3,4 \\
\hline $0,05 \mathrm{M}$ & 69 & 49 & 42 \\
\hline
\end{tabular}

A espessura de filmes originados por spin é maior do que os de dipping, pois a rotação do substrato promove a eliminação de solvente, aumentando a concentração e, assim, gerando filmes mais espessos ${ }^{2}$. Por outro lado, ao aumentar a velocidade, maior é a tensão de cisalhamento e, assim, mais fino é o filme ${ }^{3}$. Ao aumentar a concentração, maior é a disponibilidade de moléculas em solução e, assim, maior é a espessura.

Tabela 2. Rugosidade média dos filmes [nm].

\begin{tabular}{|c|c|c|c|c|}
\cline { 2 - 5 } \multicolumn{1}{c|}{} & \multicolumn{2}{c|}{ Spin } & \multicolumn{2}{c|}{ Dipping } \\
\cline { 2 - 5 } \multicolumn{1}{c|}{} & $2000 \mathrm{RPM}$ & $4000 \mathrm{RPM}$ & 10 bic & 20 bic \\
\hline $0,01 \mathrm{M}$ & 1,3 & 1,3 & 1,6 & 1,0 \\
\hline $0,05 \mathrm{M}$ & 1,5 & 0,8 & 2,7 & 2,6 \\
\hline
\end{tabular}

A rugosidade dos filmes produzidos por spin é menor que a dos produzidos por dipping devido à maior tensão de cisalhamento ${ }^{3}$. Além disso, há um efeito combinado entre a velocidade e a concentração na determinação da rugosidade, uma vez que não é observado um padrão quando se altera somente um destes parâmetros.

Por fim, as propriedades elétricas tiveram valores próximos em ambos os métodos, pois nesses recobrimentos não houve alteração de nenhuma condição química capaz de afetar os perfis elétricos.

\section{Conclusões}

Os filmes por spin são mais regulares em termos de rugosidade e mais finos que os de dipping devido à rotação do substrato. Diferenças nas propriedades elétricas de superfície serão verificadas nos testes com o par $\mathrm{HA} / \mathrm{CHI}$.

\section{Agradecimentos}

Agradeço aos integrantes do LEQUIP (Laboratório de Engenharia e Química de Produtos) pelo auxílio durante o projeto e ao CNPq pelo suporte financeiro.

\footnotetext{
${ }^{1}$ RICHARDSON, J. J. et al. Technology-drive layer-by-layer assembly of nanofilms. Science, v. 348, p. 411-422. 2015.

${ }^{2}$ CHO, J. et al. Fabrication of Highly Ordered Multilayer Films Using a Spin Self-Assembly Method. Advanced Materials, v. 13, p. 1076-1078, 2001.

${ }^{3}$ HALL, D. B.; UNDERHILL, P.; TORKELSON, J. M. Spin coating of thin and ultrathin polymer films. Polymer Engineering and Science, v. 38, p. 2039-2045, 1998
} 